\title{
Transitions of nutritional sciences
}

\author{
Nutrition is a relatively young and evolving science. Political will to reform food systems can be shown by \\ shepherding nutritional science towards population priorities and preventing its commodification.
}

E lsie Widdowson and Robert McCance were among the pioneers of modern nutritional sciences. Their work daring, meticulous and pragmatic — pushed boundaries in the understanding of food composition, population health, and the prevention of nutritional deficiencies. Widdowson and McCance ensured that the rations diet circa World War II was adequately nutritious. Their approach engendered reductionism to meet a clear public need, and the solutions were delivered through a social strategy of provision and rationing, combined with political commitment from a Ministry of Food fully aware of the damage that nutrition deficiency could wreak on the health of the people. This distillation of evidence, circumstance and power exemplifies how political will can support the best of nutritional science for meeting public priorities.

Nutritional science is considered a young and evolving field. If the work of Widdowson, McCance and others could be considered nascent in some regard, there followed decades where the model established by the reductionist approach was simply unsuitable, but often prevailed in research, industry and policy, for mitigating public priorities of complex malnutrition and diet-related disease ${ }^{1}$. Reductionism underpins much in dietary supplementation and food fortification, saturated fat and sugar replacement and product reformulation, and the definition of foods as healthy or otherwise by nutrient composition. Also in its evolution, modern nutritional science has embraced technological innovation - in genomics, metabolomics, machine learning and data network science. Machine learning brings a wealth of possibilities to our understanding of food composition, and the impact of the food on health and disease ${ }^{2}$. In their Article in this issue of Nature Food, do Valle and colleagues apply a network medicine approach to understand how polyphenols interact with target proteins for disease - again, opening up vistas of opportunity through data network science for exploring the unknowns of nutrition. A rich and contentious discourse exists on the strengths of study designs, limitations of methodology, sources of research funding and conflict of interest, and nutrient versus dietary pattern approaches to nutritional sciences. Proliferating and diverging visions of nutritional science have found patronage from a wealth of sources - but complex malnutrition and diet-related disease seem intractable, and political champions of nutritional science seem few.

Nutritional science also has a challenge of definition. It is fundamentally a life science concerned with how food and nutrients support human metabolism in health, prevention, and management of disease. In 2005 the Giessen Declaration extended the purview of nutritional sciences, or 'the new nutrition', into social and environmental domains - the unprecedented challenges humankind faces required nutritional science to be reframed ${ }^{3}$. The Giessen Declaration outlines the principles of nutritional science moving forward, including sustainability and planetary health, defining the field as "the study of food systems, food and drinks, their nutrients and other constituents, and of their interactions within and between all relevant biological, social and environmental systems"3 - a tall order of priorities and expertise for a young and evolving discipline primarily concerned largely, to date, with a reductionist approach to the prevention of disease and the promotion of biological health. And yet perhaps, as with the work of Widdowson and McCance commissioned by Minister of Food Lord Woolton, nutritional sciences should be shaped by the needs of a moment - a political architecture created for the expertise and innovation of science to coalesce with a clear public need.

And that need is clear. Following decades of decline, the number of hungry people in the world has been rising since 2014; as of 2019, 690 million people were undernourished and affordable, healthy diets were out of reach for billions (ref. $\left.{ }^{4}\right), 144$ million children under five were stunted, 47 million were wasted and 38 million were overweight ${ }^{5}$. Chronic and intractable burdens of malnutrition and diet-related disease are exacerbated further by the COVID-19 pandemic - the World Bank estimates that COVID-19 could lead to an additional 83 to 132 million undernourished adults ${ }^{5}$.

Political will is needed to deal with all aspects of this problem but shepherding the expertise and endeavour of nutritional science is the focus here. That requires shared ownership, political and scientific, of the challenge. It requires political esteem for scientific advice. Back in the 1940s, Lord Woolton is said to have engaged a reluctant government in the cause for nutritional adequacy of the ration diet. He incorporated the scientific expertise of Widdowson and McCance into a successful political strategy ${ }^{6}$. Today, for nutritional science to speak freely and have influence, there must be political awareness, observation and, where necessary, tempering of power concentrations within food systems. This is key to avoiding the commodification of nutritional science. Greater institutional support and greater public research funding are also needed, streamed for nutrition science to serve real public priorities.

The nutritional science community has responsibilities too - to build research agendas based on the needs of the moment, to engage with and communicate to the needs of policy-makers, and to equip students and professionals with the interdisciplinary confidence to meet societal needs.

The golden age of modern nutrition in the 20th century has been described as "an accident of geopolitical history" ${ }^{1}$. We propose it as a congruence of scientific endeavour with societal need, supported by political will. There are lessons for success here, perhaps, to inform the Food Systems Summit and Nutrition for Growth Summit in 2021.

Published online: 19 March 2021

https://doi.org/10.1038/s43016-021-00254-4

References

1. Mozaffarian, D., Rosenberg, I. \& Uauy, R. BMJ 361, k2392 (2018).

2. Barabási, A.-L., Menichetti, G. \& Loscalzo, J. Nat. Food 1 33-37 (2020).

3. Beauman, C. et al. Public Health Nutr. 8, 695-698 (2005).

4. Future Food Systems: For People, Our Planet, and Prosperity (The Global Panel on Agriculture and Food Systems for Nutrition, 2020).

5. Carducci, B. et al. Nat. Food 2, 68-70 (2021)

6. Lang, T. Feeding Britain: Our Food Problems and How to Fix Them (Pelican, 2021). 